Diabetes

Edited by Tim Dornan DM FRCP, Consultant Physician, Hope Hospital, Salford, Manchester

\title{
Glycaemic management of type 2 diabetes
}

Simon Page MD FRCP, Department of Diabetes, Endocrinology and Clinical Nutrition, University Hospital NHS Trust, Queen's Medical Centre, Nottingham

Clin Med 2004;4:302-6

\section{Introduction}

There is a pandemic of type 2 diabetes. Global estimates predict a doubling of cases over the next 20 years $^{1}$ and a recent Australian survey found a $15 \%$ population prevalence of impaired glucose tolerance (IGT). ${ }^{2}$ The reasons are complex, and include adoption of a 'western' lifestyle in developing countries and a soaring prevalence of obesity in developed countries. Type 2 diabetes is a powerful risk factor for ischaemic heart disease. Even 'prediabetic' states increase cardiovascular risk because glucose

Table 1. Diagnostic criteria for diabetes.

\begin{tabular}{|c|c|c|}
\hline Normoglycaemia & 'Pre-diabetes' & Diabetes* \\
\hline $\begin{array}{l}\text { FPG }<6.0 \mathrm{mmol} / \mathrm{l} \\
(<110 \mathrm{mg} / \mathrm{dl})\end{array}$ & $\begin{array}{l}\text { IFG** } \\
\text { FPG } 6.0-6.9 \mathrm{mmol} / \mathrm{l} \\
(110-126 \mathrm{mg} / \mathrm{dl})\end{array}$ & $\mathrm{FPG} \geqslant 7.0 \mathrm{mmol} / \mathrm{l}(126 \mathrm{mg} / \mathrm{dl})$ \\
\hline \multirow[t]{2}{*}{$\begin{array}{l}\text { †2-hr PG }<7.8 \mathrm{mmol} / \mathrm{l} \\
(140 \mathrm{mg} / \mathrm{dl})\end{array}$} & $\begin{array}{l}\mathrm{IGT}^{\dagger} \\
\text { 2-hr PG 7.8-11.0 mmol/I } \\
(140-200 \mathrm{mg} / \mathrm{dl})\end{array}$ & $\begin{array}{l}{ }^{2} 2-\mathrm{hr} P G \geqslant 11.1 \mathrm{mmol} / \mathrm{l} \\
(200 \mathrm{mg} / \mathrm{dl})\end{array}$ \\
\hline & & $\begin{array}{l}\text { Symptoms of diabetes and } \\
\text { random } \mathrm{PG} \text { concentration } \\
\geqslant 11.1 \mathrm{mmol} / \mathrm{l}(200 \mathrm{mg} / \mathrm{dl})\end{array}$ \\
\hline
\end{tabular}

* The measurement should be repeated on a subsequent day to confirm a diagnosis of diabetes in an asymptomatic patient.

** Fasting is defined as no caloric intake for at least 8 hours.

$\dagger$ Oral glucose tolerance test: $75 \mathrm{~g}$ anhydrous glucose dissolved in water with measurement of fasting and 2-hour plasma glucose.

$F P G=$ fasting plasma glucose, IFG = impaired fasting glucose, $I G T=$ impaired glucose tolerance, $P G=$ plasma glucose.
Glycosuria cannot be used to diagnose diabetes; it can be found in normoglycaemic subjects who have a low renal glucose threshold. A finding of glycosuria should prompt laboratory glucose measurements. IGT and impaired fasting glucose (IFG) are considered prediabetic states. Key points about them are listed in Table 2.

\section{Prevention of type 2 diabetes}

Progression from IGT to type 2 diabetes can be delayed, although it is less certain that true prevention is achievable. In the Diabetes Prevention Program, ${ }^{4} 3,234$ subjects with IGT were randomised to lifestyle intervention, metformin, or standard healthcare. Lifestyle change reduced progression to type 2 diabetes by $58 \%$ compared with standard healthcare and was effective in all age groups. Metformin reduced progression by $31 \%$, but only in younger, more overweight individuals. Similar results for lifestyle intervention were reported in the Diabetes Prevention Study. ${ }^{5}$ Subjects in these trials received considerable support from research staff. On average, subjects took about $150 \mathrm{~min}$ utes of moderate intensity exercise weekly and achieved an average weight loss of 3-6 kg. In the real world, however, many individuals do not achieve these modest results so metformin is of interest as an alternative.

Acarbose, an alpha-glucosidase inhibitor, reduced progression from IGT to type 2 diabetes by $25 \%,{ }^{6}$ but protection did not persist after drug withdrawal. The

Table 2. Key points about impaired glucose tolerance (IGT) and impaired fasting glucose (IFG).

- IGT and IFG are not clinical entities but should be considered as risk categories for CVD and/or future diabetes

- IGT and IFG are not interchangeable; only $20 \%$ of subjects with an abnormality of glucose regulation will have both IGT and IFG

- IGT is 2-3 times more common than IFG in most populations

- IGT is a better predictor of CVD risk

$\mathrm{CVD}=$ cardiovascular disease 
insulin-sensitising thiazolidinedione, troglitazone, reduced by $58 \%$ compared with placebo the risk of type 2 diabetes in Hispanic women with a past history of gestational diabetes. ${ }^{7}$ Protection appeared more sustained than with acarbose as there was no increase in cases of type 2 diabetes for eight months after drug withdrawal. Finally, the anti-obesity agent orlistat has recently been shown to reduce progression from IGT to type 2 diabetes by $37 \% .^{8}$

\section{Conclusions from these studies}

The first conclusion that can be drawn from these studies is that lifestyle change, if achieved, is a potent means of reducing the risk of type 2 diabetes. This has implications for individuals and also for governments responsible for public health, transport and food policies. Secondly, it is unrealistic to expect lifestyle measures alone to work so a combined approach is needed. ${ }^{9}$ Metformin is currently the 'best buy', but ongoing trials with the thiazolidinedione rosiglitazone and the prandial glucose regulator nateglinide will guide management of prediabetes in future.

\section{United Kingdom Prospective Diabetes Study (UKPDS)}

The implications of the UKPDS for cardiovascular prevention are discussed in an accompanying article. Some points specific to glycaemic management are: ${ }^{10,11}$

- There were no differences in glucose control or microvascular end points between patients treated with chlorpropamide, glibenclamide or insulin.

- Metformin, used as primary therapy for overweight patients (>120\% ideal body weight) reduced both microvascular and macrovascular end points, even though glucose control was similar to other therapies.

- Metformin was the only therapy not associated with weight gain.

- The alpha-glucosidase inhibitor acarbose was poorly tolerated; half the patients randomised to acarbose

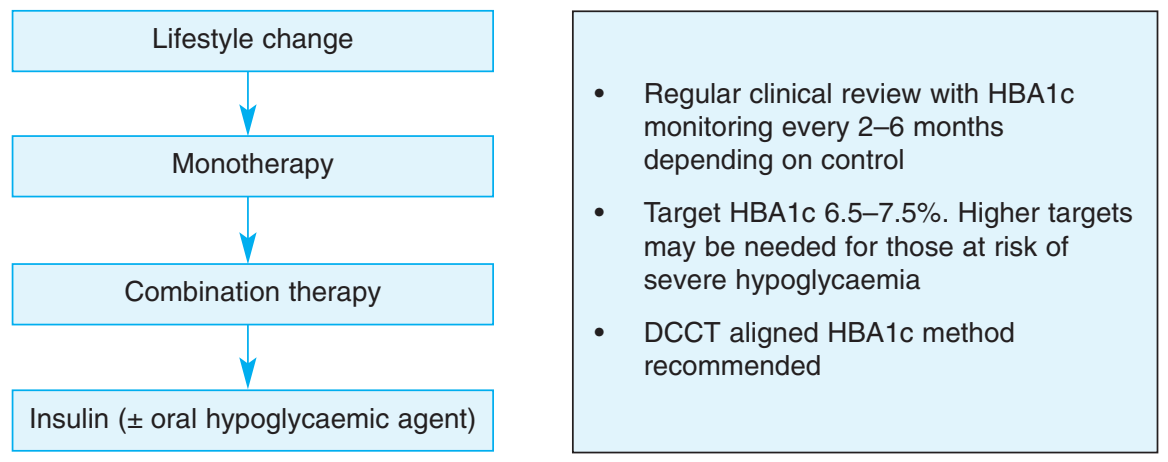

Fig 1. Stepped care approach to diabetes treatment (DCCT $=$ The Diabetes Control and Complications Trial; $\mathrm{HbA}_{1 \mathrm{c}}=$ haemoglobin $\left.\mathrm{A} 1 \mathrm{c}\right)$.

withdrew due to unacceptable side effects.

\section{Clinical management guidelines}

Of the myriad published diabetes management guidelines, those of the National Institute for Clinical Excellence (NICE) ${ }^{12}$ are likely to influence clinical management in the UK. They emphasise the importance of regular patient assessment because of the progressive nature of type 2 diabetes. A stepped approach is advocated for glucose control (Fig 1).

\section{Lifestyle change}

For the established patient, dietary change remains the cornerstone of initial management, with an emphasis on encouraging overweight patients to lose weight and take more exercise. The Nutritional Subcommittee of Diabetes $\mathrm{UK}^{13}$ has recently updated its recommendations for diet composition (Table 3).
'Diabetic' foods, vitamin supplements (except in particular conditions such as cystic fibrosis), antioxidants and 'herbal' remedies are not recommended. Translating these rather 'dry' recommendations into advice to patients on what to eat requires input from a trained dietitian. Practical advice on implementation of these recommendations is available. ${ }^{13}$

\section{Monotherapy}

\section{Metformin}

Metformin is recommended as first-line monotherapy in overweight or obese patients who have not achieved optimal glucose control with a diet. ${ }^{12}$ Metformin is preferred because, as mentioned above, unlike other oral hypoglycaemic agents it does not cause weight gain. There is also a suggestion both from UKPDS ${ }^{11}$ and another recent study $^{14}$ that metformin may also have cardioprotective potential.

Up to $20 \%$ of patients have gastrointestinal side effects on metformin and

Table 3. Dietary recommendations of Diabetes UK.

\begin{tabular}{ll} 
Macronutrient & Recommendation \\
\hline Protein & $<1 \mathrm{~g} / \mathrm{kg}$ body weight \\
Total fat & $<35 \%$ energy intake \\
Saturated fat & $<10 \%$ energy intake \\
Cis-monounsaturated fat & $10-20 \%$ energy intake \\
Total carbohydrate & $40-60 \%$ energy intake \\
Sucrose & Up to $10 \%$ of daily energy intake \\
& (provided in context of a healthy diet) \\
Fibre & No quantitative recommendations \\
Salt & $<6$ g/day
\end{tabular}




\section{Key Points}

There is a pandemic of type 2 diabetes; its prevalence is set to double over the next two decades

There are also at least as many cases of 'prediabetes'; progression to diabetes can be limited by lifestyle measures and drug therapy

The UK Prospective Diabetes Study showed metformin, insulin and sulphonylureas to be equally effective in controlling hyperglycaemia

Type 2 diabetes is a progressive disease, so a 'stepped care' approach, progressing from monotherapy to drug combinations, is needed

KEY WORDS: cardiovascular disease, glucose intolerance, insulin, oral hypoglycaemics, stepped care, therapy, type 2 diabetes some cannot tolerate this drug. Initiating treatment with a low dose and gradually titrating upwards according to the haemoglobin $\mathrm{Alc}\left(\mathrm{HbA}_{1 \mathrm{c}}\right)$ response can reduce side effects. Metformin is contraindicated in patients with renal failure (serum creatinine $\geq 130 \mu \mathrm{mol} /$ litre $(\mathrm{mcmol} / \mathrm{l}),{ }^{12}$ decompensated cardiac or hepatic failure.

\section{Secretagogues}

Metformin can also be considered in patients who are not overweight, although insulin secretagogues are generally advocated as first-line therapy in this group. A range of these agents is available (Table 4).

There is little to choose between insulin secretagogues in terms of efficacy and hypoglycaemic risk, so selection is a matter of personal preference and experience. Long-acting preparations offer advantages in patients in whom concordance is a problem. Prandial glucose regulators may help patients with nonroutine daily lifestyles.

\section{Glitazones}

The glitazones, rosiglitazone and pioglitazone, are newer agents whose primary mechanism of action is to reduce insulin resistance in peripheral tissues, especially skeletal muscle. Both agents have recently been granted a monotherapy licence. Their place in initial therapy of type 2 diabetes remains unclear but their mechanism of action suggests they are an appropriate monotherapy choice in met- formin-intolerant overweight patients. Preliminary data suggest that the glitazones may reduce cardiovascular risk, but results from ongoing clinical outcome studies are awaited.

\section{Acarbose}

Another monotherapy option is acarbose but, as mentioned above, its poor tolerability makes it a less favoured choice with many clinicians (and patients!). Side effects can be lessened by starting with a low dose and titrating up slowly over several weeks.

\section{Orlistat}

The anti-obesity agent orlistat may also be considered as an adjunct to lifestyle advice. However, it should be prescribed only to adults with a body mass index of $28 \mathrm{~kg} / \mathrm{m}^{2}$ or above who have lost $2.5 \mathrm{~kg}$ by diet and increased activity in the month prior to their first prescription. It will not achieve rapid control of blood glucose and should be combined with conventional oral hypoglycaemic agents rather than used as monotherapy.

\section{Combination therapy}

UKPDS clearly demonstrated a progressive requirement for multiple therapies. ${ }^{15}$ After nine years of monotherapy with diet, insulin or sulphonylurea, $9 \%, 28 \%$ and $24 \%$ of the patients, respectively, achieved $\mathrm{HbA}_{1 \mathrm{c}}$ levels below 7\%. In obese patients randomised to metformin, 13\% attained $\mathrm{HbA}_{1 \mathrm{c}}$ levels below $7 \%$.

Combination therapy is required when target $\mathrm{HbA}_{1 \mathrm{c}}$ levels are not achieved by lifestyle change combined with appropriate monotherapy. Before adding additional tablets it is worth checking the patient's concordance with lifestyle advice and tablets, although disease progression is clearly an alternative explanation for not achieving target levels. Assuming concordance is satisfactory, NICE advocates a combination of metformin and an appropriate insulin secretagogue. ${ }^{12}$

Glitazones are not recommended in combination therapy unless a patient is unable to take 'standard' combination therapy or where this is not achieving optimal glucose control. It is important to emphasise that substituting a glitazone for either metformin or an insulin secretagogue may result in a temporary deterioration of glucose control because the glitazone takes six months to work. Adding a glitazone to standard combination therapy for three months as triple therapy before withdrawing one of the standard agents may overcome this problem.
Table 4. Currently available insulin secretagogues (see British National Formulary for dose schedules.

\begin{tabular}{lll}
$\begin{array}{l}\text { Long-acting } \\
\text { (once daily) }\end{array}$ & $\begin{array}{l}\text { Short-acting } \\
\text { (2 or } 3 \text { times daily) }\end{array}$ & $\begin{array}{l}\text { Ultra short-a } \\
\text { (prandial glucos } \\
\text { immediately b }\end{array}$ \\
\hline $\begin{array}{l}\text { Glibenclamide* } \\
\text { Glimepiride }\end{array}$ & $\begin{array}{l}\text { Tolbutamide } \\
\text { Gliclazide }\end{array}$ & $\begin{array}{l}\text { Repaglinide } \\
\text { Nateglinide** }\end{array}$ \\
\hline
\end{tabular}

* Avoid in elderly people (>70 years) or those with renal failure due to risk of severe and prolonged hypoglycaemia.

** Licensed for use only in combination with metformin 


\section{Indications for insulin}

The progressive nature of type 2 diabetes makes insulin therapy more likely with increasing disease duration. About 50\% of patients with type 2 diabetes for 15 years or longer need insulin.

Certain characteristics predict patients likely to need insulin therapy earlier: ${ }^{16}$

- lean patients

- younger patients

- higher fasting glucose at diagnosis

- lower beta cell reserve at diagnosis.

Lean patients are likely to be less insulin resistant and have more severe insulin deficiency at presentation. Up to $15 \%$ of such patients may have positive antibody markers for type 1 diabetes, a condition termed latent autoimmune diabetes of adults. Indications for insulin therapy are summarised in Table 5.

Insulin should not be recommended solely on $\mathrm{HbA}_{1 \mathrm{c}}$ results. Many patients with type 2 diabetes are elderly, so practical considerations like manual dexterity, eyesight and social circumstances must be taken into account. The risk of hypoglycaemia is higher with insulin therapy $(2.3 \%$ per annum) than with insulin secretagogues ( $1.6 \%$ per annum) and an elderly patient living alone at home with few symptoms and a raised $\mathrm{HbA}_{1 \mathrm{c}}$ may be safer on tablets than on insulin.

The timing of insulin initiation is important. Clinical trial and audit data suggest that insulin initiation in type 2 diabetes will lower $\mathrm{HbA}_{1 \mathrm{c}}$ levels by about
Table 5. Indications for insulin therapy.

Long-term
Poor glucose control (above target
HbA1c \pm symptoms) despite adequate
concordance with lifestyle change and
combination therapy
Patient preference
Short-term
Acute myocardial infarction
Acute intercurrent illness
Elective surgical procedures
Short-term glucocorticoid therapy if
glucose control inadequate on oral
agents
Gestational diabetes with inadequate
glucose control despite diet change

$\mathrm{HbA1c}=$ haemoglobin $\mathrm{A} 1 \mathrm{c}$.

$2 \%$ on average, associated with a weight gain of 3-5 kg. In those reports, pre-insulin $\mathrm{HbA}_{1 \mathrm{c}}$ levels were generally over $9 \%$ and patients with very high $\mathrm{HbA}_{1 \mathrm{c}}$ levels $(>11 \%)$ did best. In patients with $\mathrm{HbA}_{1 \mathrm{c}}$ levels of 7.5-9\% there is less evidence that early transfer to insulin achieves such impressive results and each case should be judged on merit.

\section{Which regimen?}

Numerous options are available in choosing a regimen using combinations of short- and intermediate-acting human insulin, pre-mixed preparations and/or insulin analogues. Regimens should be individualised according to the patient's needs and circumstances and the advice of a diabetes specialist nurse is invalu- able. Commonly used insulin regimens are summarised in Table 6 . Weight gain is an almost universal consequence as insulin reduces the glycosuria of poor glycaemic control. Continuing metformin therapy when transferring to insulin limits the degree of weight gain and is generally recommended. ${ }^{12,17}$

\section{Conclusions}

Type 2 diabetes is a disease that progresses inexorably from the pre-diabetic state of IGT to the need for insulin to control hyperglycaemia. Early intervention delays its development. Once established, stepped care is needed to control hyperglycaemia. However, it cannot be overemphasised that hyperglycaemia control is only one facet of management of type 2 diabetes. Meticulous attention to cardiovascular risk factor reduction and lifestyle change (discussed elsewhere in this section) are at least as important as management of glycaemia.

\section{Conflict of interest}

Dr Page has undertaken clinical trials sponsored by Novo Nordisk,

GlaxoSmithKline (GSK), Takeda and Servier. He has received speaker honoraria from NovoNordisk, GSK, Lilly, Aventis, Pfizer and Servier.

\section{References}

1 Zimmet P. The burden of type 2 diabetes: are we doing enough? Review. Diabetes Metab 2003;29(4 Pt 2):6S9-18.

Table 6. Insulin regimens for type 2 diabetes.

\begin{tabular}{ll} 
Regimen & Advantages \\
\hline Once daily & Simple \\
& Can be combined with continued oral hypoglycaemic therapy \\
& Dose titrated against fasting glucose results \\
& Can be administered by relative or district nurse if necessary \\
Twice daily isophane & Relatively simple \\
& Controls symptoms \\
& Low risk of hypoglycaemia \\
Twice daily pre-mixed & Relatively simple \\
& Suitable for patients with a routine daily lifestyle \\
Multiple injection & Greater flexibility with meals \\
(basal-bolus) regimen & Suitable for patients with non-routine daily lifestyle \\
& Newer short- and long-acting analogues allow good \\
& glucose control at low risk of hypoglycaemia
\end{tabular}

Disadvantages

Daytime hyperglycaemia can be a problem

Morning and evening hyperglycaemia likely due to inadequate insulin post-breakfast and post-evening meal

Increased risk of hypoglycaemia pre-lunch and overnight

Four or more injections per day

More complex regimen needing good understanding by patient 
2 Dunstan DW, Zimmet PZ, Welborn TA, De Courten MP et al. The rising prevalence of diabetes and impaired glucose tolerance: the Australian Diabetes, Obesity and Lifestyle Study. Diabetes Care 2002;25:829-34.

3 Ford ES, Giles WH. A comparison of the prevalence of the metabolic syndrome using two proposed definitions. Diabetes Care 2003;26:575-81.

4 Knowler WC, Barrett-Connor E, Fowler SE, Hamman RF et al; Diabetes Prevention Program Research Group. Reduction in the incidence of type 2 diabetes with lifestyle intervention or metformin. $N$ Engl J Med 2002;346:393-403.

5 Tuomilehto J, Lindstrom J, Eriksson JG, Valle TT et al; Finnish Diabetes Prevention Study Group. Prevention of type 2 diabetes mellitus by changes in lifestyle among subjects with impaired glucose tolerance. N Engl J Med 2001;344:1343-50.

6 Chiasson JL, Josse RG, Gomis R, Hanefeld $\mathrm{M}$ et al; STOP-NIDDM Trial Research Group. Acarbose for prevention of type 2 diabetes mellitus: the STOP-NIDDM randomised trial. Lancet 2002;359:2072-7.

7 Buchanan TA, Xiang AH, Peters RK, Kjos SL et al. Preservation of pancreatic beta-cell function and prevention of type 2 diabetes by pharmacological treatment of insulin resistance in high-risk hispanic women. Diabetes 2002;51:2796-803.

8 Torgerson JS, Hauptman J, Boldrin MN, Sjostrom L. XENical in the prevention of diabetes in obese subjects (XENDOS) study: a randomized study of orlistat as an adjunct to lifestyle changes for the prevention of type 2 diabetes in obese patients. Diabetes Care 2004;27:155-61.

9 Zimmet P, Shaw J, Alberti KG. Preventing Type 2 diabetes and the dysmetabolic syndrome in the real world: a realistic view. Review. Diabet Med 2003;20:693-702.

10 Intensive blood-glucose control with sulphonylureas or insulin compared with conventional treatment and risk of complications in patients with type 2 diabetes (UKPDS 33). UK Prospective Diabetes Study (UKPDS) Group. Lancet 1998;352: 837-53.

11 Effect of intensive blood-glucose control with metformin on complications in overweight patients with type 2 diabetes (UKPDS 34). UK Prospective Diabetes Study (UKPDS) Group. Lancet 1998;352: 854-65.

12 National Institute for Clinical Excellence. Management of Type 2 diabetes. Management of blood glucose. Clinical guideline G. Sept 2002. www.nice.org.uk

13 Connor H, Annan F, Bunn E, Frost G et al; Nutrition Subcommittee of the Diabetes Care Advisory Committee of Diabetes UK. The implementation of nutritional advice for people with diabetes. Diabet $\mathrm{Med}$ 2003;20:786-807.

14 Abbasi F, Chu JW, McLaughlin T, Lamendola $\mathrm{C}$ et al. Effect of metformin treatment on multiple cardiovascular disease risk factors in patients with type 2 diabetes mellitus. Metabolism 2004;53: 159-64.

15 Turner RC, Cull CA, Frighi V, Holman RR. Glycemic control with diet, sulfonylurea, metformin, or insulin in patients with type 2 diabetes mellitus: progressive requirement for multiple therapies (UKPDS 49). UK Prospective Diabetes Study (UKPDS) Group. JAMA 1999;281:2005-12.

16 Matthews DR, Cull CA, Stratton IM, Holman RR, Turner RC. UKPDS 26: Sulphonylurea failure in non-insulindependent diabetic patients over six years. UK Prospective Diabetes Study (UKPDS) Group. Diabet Med 1998;15:297-303.

17 Yki-Jarvinen H. Combination therapy with insulin and oral agents: optimizing glycemic control in patients with type 2 diabetes mellitus. Review. Diabetes Metab Res Rev 2002;18(Suppl 3):S77-81. 